\title{
Bipartisan Proposal Calls for SGR Repeal
}

The Washington Post (11/1, Carey) reports a bipartisan group of legislators has agreed on a framework replacing the "problematic" Medicare payment formula in an attempt to end the annual Sustainable Growth Rate (SGR) or "doc fix" debate. The current system is set to reduce Medicare physician payments by approximately $25 \%$ on Jan. 1 without Congressional intervention. Senate Finance Committee Chairman Max Baucus (D-MT) and House Ways and Means Committee Chairman Dave Camp (R-MI) introduced a draft proposal that would "encourage care management services for individuals with complex chronic care needs through the development of new payment codes for such services, as well as leverage physician-developed standard of care guidelines to avoid the unnecessary provision of services". The Committees value your feedback on this proposal. Please submit written comments to the Finance SGR comments mailbox at sgrcomments@finance.senate.gov and the Ways \& Means SGR comments mailbox at sgrwhitepaper@mail.house.gov by Tuesday, November 12, 2013.

Dr. John Noseworthy, Mayo Clinic president and CEO, said in a press release he was pleased to see a bipartisan effort to replace the outdated SGR. The release went on to say that the Mayo Clinic will the initiatives and respond to Congress' request to provide further comments.

Richard A. Robbins MD 